11 of 27 Pseudomonas, 5 of 11 Proteus mirabilis, and in none of 4 Klebsiella and $1 P$. vulgaris infection.

In none of these studies was selection of patients based on demonstrated sensitivity of the causative organism to carbenicillin combined with resistance to other drugs. If this criterion were adopted, what are the indications likely to be ? First, and without question, Pseudomonas infections. E. coli is a sensitive species, but it is also normally sensitive to many other drugs more agreeable to administer than this one, and resistance to every one of them is improbable. It was stated at the symposium that "all strains of Proteus" are sensitive, but this is mistaken. $P$. mirabilis is normally sensitive, but if it forms penicillinase (and many strains do) it is not. This was clearly stated in the original paper announcing the discovery of carbenicillin ${ }^{4}$ and also emphasized by L. P. Garrod and F. O'Grady in their well-known book. ${ }^{5} P$. mirabilis is specifically named as a cause of infection in four of these papers, but none of them makes any reference to this distinction or states whether the strains concerned formed penicillinase. If they did, failure is not surprising; if they did not, the infection might have responded equally well to ampicillin. The uncommon indoleforming Proteus species are sensitive to carbenicillin alone among the penicillins, but the single representative of these, a $P$. vulgaris infection, was a failure. Klebsiella are well known to be resistant, and it is not surprising that these infections did not respond.

It is not too harsh a judgement on this drug to conclude that the outpatient treatment of Pseudomonas infections is almost the only indication for it. These differ from most others in being insusceptible to any other oral therapy. A convincing case for its use in other infections has not yet been made out.

1 fournal of Infectious Diseases, 1973, 127, Suppl., May.

2 Bran, J. L., Karl, D. M., and Kaye, D., Clinical Pharmacology and Therapeutics, $1971,12,525$.

Wallace, J. F., et al., Antimicrobial Agents and Chemotherapy, 1971, 10, 223.

- Knudsen, E. T., Rolinson, G. N., and Sutherland, R., British Medical fournal, 1967, 3, 75 .

5 Garrod, L. P., and O'Grady, F., Antibiotic and Chemotherapy, 3rd edn., Table XIII. Edinburgh, Churchill Livingstone, 1971.

\section{Epidemiology of Anorexia Nervosa}

The clinical features of anorexia nervosa in both sexes have recently been reviewed in these columns. ${ }^{12}$ Now $R$. E. Kendell and colleagues ${ }^{3}$ have reported new epidemiological data with which they attempt to validate the prevalent views that anorexia nervosa is commoner than average in the middle-class, ${ }^{4}$ rare in negroes, ${ }^{56}$ and increasing in frequency. ${ }^{5} 7$ Their data were obtained from the psychiatric case registers of Northeast Scotland, ${ }^{8}$ Camberwell, ${ }^{9}$ and Monroe County in New York State. ${ }^{10}$

The North-east Scotland register covers Aberdeen and its environs, with a total population of 473,370 in 1966. In the fouryear period 1966-9 30 new cases of anorexia nervosa were registered, 28 female and 2 male. The annual occurrence was $6,4,7$, and 13 . Their mean age was $24 \cdot 7$ years, and the median age was 20.3 years. This gave an average annual incidence of 1.6 per 100,000 population and a sex-age specific rate for the 27 females aged 15-34 years of $10 \cdot 8$ per 100,000 . According to parental social class a greater proportion of patients were in the Registrar General's social classes 2 and 3 than were the other cases on the register, but the proportion was the same as in the general population of the area.

The Monroe County register covers the city of Rochester and its environs in New York State, with a total population of 586,000 in 1960 rising to 712,000 in 1970 , of which 25,000 are reported to be non white. During the decade 1960-9 24 cases of anorexia nervosa were recorded of whom 17 were female and 7 male. The cases in successive years were: $3,0,1,2,3,3,3,0$, 3 , and 6 . Their mean age was $22 \cdot 2$ years and median age between 15 and 19, with no significant difference in age between the sexes and no non-white patients. The average annual incidence was 0.37 per 100,000 population, but the sex-age specific rate for females aged 15-34 years was only 0.8 per 100,000 . Social class data were not recorded.

The Camberwell register covers an area in South-east London with a population of 172,000 , of whom 10,000 are coloured immigrants. From the start of the register in 1965 up to 1971 eight patients with anorexia nervosa were recorded, all female, with a mean age of 21.6 years. None was reported in the first four years; there were 2 in 1969 and 1970 and 4 in 1971. The average annual incidence was 0.66 per 100,000 population and the sex-age specific rate for females aged 15-34 years was $4 \cdot 1$ per 100,000 . Five of these patients had parents in social classes 1 or 2 , which was a highly significant excess over other register patients and the general population. One patient was of Indian origin.

These observations can be compared with those of $S$. Theander, ${ }^{11}$ in Sweden, who calculated an average annual incidence over a 30 -year period of 0.24 per 100,000 population, but in the final decade the figures rose to 0.45 per 100,000 .

It can be seen that there was a fourfold difference in average annual incidence and a more than tenfold difference in sexage specific annual incidence between North-east Scotland and Monroe County, with Camberwell occupying an intermediate position, but these variations seem unlikely to be due to genuine differences in incidence. Kendell and colleagues readily admit the possibility of divergent diagnostic criteria and inconsistent referral of cases to psychiatrists and are consequently cautious in their conclusions.

Only the Camberwell series showed a definite class bias. In each area the numbers of registered cases of anorexia nervosa increased over the years of the study. This could be an artefact, as it may take some years from the start of a register for it to reach a satisfactory level of reliability and completeness. ${ }^{12}$ But the findings of Theander ${ }^{11}$ over a much longer period suggest that anorexia nervosa may be truly on the increase. At any rate this study is more than merely an illustration of the pitfalls of psychiatric case registers, since it provides data on the epidemiology of anorexia nervosa for future comparisons when these and other registers have been in operation over a longer period.

${ }^{1}$ British Medical fournal, 1971, 4, 183.

2 British Medical fournal, 1972, 4, 686. Medicine, 1973, 3, 200 .

4 Dally, P. J., Anorexia Nervosa, London, Heinemann, 1969.

5 Bruch, H., Fournal of Nervous and Mental Disease, 1965, 141, 555.

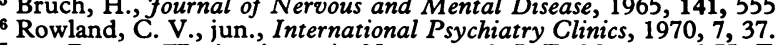

7 von Baeyer, W., in Anorexia Nervosa, ed. J. E. Meyer and H. Feldman, p. 150. Stuttgart, Thieme, 1965.

Baldwin, J. A., Innes, G., Millar, W. M., Sharp, G. A., and Dorricott, N., British fournal of Preventive and Social Medicine, 1965, 19, 38.

${ }^{9}$ Wing, L., Bramley, C., Hailey, A., and Wing, J. K., Social Psychiatry, $1968,3,116$.

10 Gardner, E. A., Miles, H. C., Iker, H. P., and Romano, J., American Fournal of Public Health, 1963, 53, 1269.

11 Theander, S., Acta Psychiatrica Scandinavica, 1970, suppl. 214.

12 Baldwin, J. A., Aspects of the Epidemiology of Mental Illness; Studies in Record Linkage. London, Churchill Livingstone, 1972. 